\title{
Perspectives on Integrated Fire Management in Brazilian public policies
}

\author{
Leonardo Debossan de Oliveira ${ }^{*}$, Wellington Lopes Assis ${ }^{2 *}$
}

\author{
${ }^{1}$ Instituto de Geociências da Universidade Federal de Minas Gerais (IGC/UFMG), Associação Brigada 1 \\ (B1), Belo Horizonte, Brasil \\ ${ }^{2}$ Instituto de Geociências da Universidade Federal de Minas Gerais (IGC/UFMG) \\ *E-mail para contato: leodebossan@gmail.com, assisw@gmail.com
}

\begin{abstract}
The aim of this paper is to present a methodology for Integrated Fire Management (IFM) seeking prevention, control and suppression of forest fires in Conservation Units with integral protection in Minas Gerais through the proposition of a pilot-project in State Park of Serra do Rola Moça. IFM is a strategy used for different objectives, such as, restoration of endemic vegetation, landscape transformation, wildlife maintenance and fire prevention. The implementation of IFM in Brazil is recent, with its first experiences in three Federal Conservation Units in the North region. This paper is composed of two stages. The first stage encompasses data production and collection from 2019 through 2021, in the Conservation Unit with integral protection of State Park of Serra do Rola Moça in which the following steps will be followed: meteorological data will go through systematization, data collection on areas more frequently affected by fires will be gathered and forest strata of greater relevance will be identified, in order to establish the polygons for prescribed burning. The meteorological data will be obtained through the automatic station of the National Institute for Meteorology (INMET) located at the Park's Integrated Center. The Fire incidence analysis will occur through investigation of time and place data for each occurrence, its burnt area and perimeter available in the Forest Fires Occurrences Reports (ROIs).The forest diagnosis will be performed using satellite imageprocessing, by means of the false color system NDVI, using the software Spring and later on Quantum GIS for vectorization of the identified areas. Second stage concerns implementation. To achieve this, field work for characterization and validation of pre-established polygons will be conducted initially observing the factors of topography and fuel, to assess the feasibility of the procedure and to establish the burn mosaic. With this, we aim to establish a methodological procedure to support the development of regulation norms to implement IFM in Conservation Units with integral protection in Minas Gerais in accordance with the current legislation.
\end{abstract}

Keywords: fire integrated management, prescribed burning, methodological procedures, regulation, legislation. 